\title{
Technical Production System of lebol: A Local Dairy Product in Cameroon with Higher Potential
}

\author{
D. F. R. Dazeck ${ }^{1,2}$, H. C. Edima ${ }^{2}$ and Nso E. Jong ${ }^{2}$ \\ ${ }^{1}$ Institute for Agricultural Research for Development, Cameroon \\ ${ }^{2}$ National School of Agro-Industrial Sciences, Cameroon \\ *Corresponding author
}

\section{A B S T R A C T}

\section{Keywords}

Dairy products, Lebol, Production System,Cameroon

Article Info

Accepted:

12 March 2021

Available Online:

10 April 2021
This work is carried out to describe the technical production system of lebol with the aim to diagnose the constraint which affect the valorization of this product and recommend the correctives measures to be implemented to allow the improvement of the producers. To meet the goal, a survey was carried out among dairy processing units in the North Region of Cameroon, which is one of the main milk production zones in the country. For this purpose, a questionnaire and a check list, were used to collect data to evaluate the application of Good Hygienic Practices and Good Manufacturing Practices in relation with the requirement of Codex Alimentarius. The main result shows that $96 \%$ of the producers are women. There is only one process type in the production of lebol with a spontaneous fermentation. $80 \%$ of producers use pendidam (sour fermented milk) and $20 \%$ kindirmou(fermented milk). In addition, Good Hygienic Practices are not applied by all the operator. However, lebol is tasty, and used as flavors enhancer. It is also used in traditional therapies and in cosmetics. Definitively, lebol is a local dairy product with a higher economic, culinary and therapeutic potentials, but the main critical point which limit his valorization is the formulation of starter.

\section{Introduction}

Cameroon is milk producer country with many local dairy products with varied organoletptic properties that are pendidam (skimmed fermented milk); kindirmou (fermented whole milk) and lebol (dehydrated fats from milk). However, the production system for these local dairy products remain traditional
(Essomba et al., 2005; Libouga et al., 2005; Edima et al., 2013).

Although appreciated by consumers, thanks to their atypical aromas and textures they pose a problem quality conformity of the final product as they vary from operator to operator. However, these products for the most part (pendidam, kindirmou, biradam), require a 
cold chain which is conspicuously absent in the production systems of villages and countryside that do not always have electricity for their preservation. Lebol does not need to be cold for preservation. It is appreciated by consumers for his flavor and widely used for its therapeutic, organoleptic and cosmetic properties. However, this local dairy product is not valorized and does not allow empowerment of producers who are the main consumers of their products (Edima et al., 2014).

In the Fulani language, lebol refers to the dehydrated fat of milk obtained after churning a fermented cream of cow milk(Essomba et al., 2005; Edima et al., 2014). It remains low income product because it is not wholesome.

This is a consequence of inappropriate processing and preservation methods (Edima et al., 2014). In order to upgrade his economic status, an appropriate technical system of production of lebol has to be developed. Knowledge of all components of the system would allow to identify flaws, permitting the corrective actions to be carried out. This work is carried out to describe the different components of the local technological system of lebol production in North Region of Cameroon.

\section{Materials and Methods}

\section{Zone of Study}

The study was conducted in the North Region of Cameroon. It is one of the main milk production zones in Cameroon. This region has four administrative divisions: Bénoué, Mayo-louti, Mayo-Rey and Faro; and 21 sub divisions. This administrative distribution has been reconfigured into 51 Zootechnical Veterinary Centers (MINEPIA, 2015), each of which included the dairy units in which this study was conducted.

\section{Analysis of the Production System of Lebol}

A survey was carried out in order to describe the various components of the technical system of lebol production in North Region of Cameroon. It took into account the accessibility of the production unit and the availability of operators to answer the questions asked. A questionnaire was used in which the following topics are assessed : the identification of the operator's, the working environment, the supply and storage of the raw material, packaging and preservation, quality criteria and the use of final product. The informations were collected through interviews (in Fulfuldé and French) and visual observations done.

\section{Manufacturing Process Analysis}

To evaluate the local method of processing lebol, a checklist (Codex Alimentarius, 2011) was established to collect information on inputs (nature and quantity) and unit operations (designations, parameters and materials used). Information was collected by observing the transformation of milk into lebol. A stopwatch and thermometer (HANNA brand) were used to measure parameters (time and temperature).

\section{Results and Discussion}

\section{Characterization of operators operating in the lebol manufacturing chain}

In order to characterize the different actors involved in the lebol processing chain, informations about operators were collected (Table 1). It appears that out of a total of 106 operators surveyed, $96 \%$ of the people involved in this sector are women.

These results are justified insofar as the woman in the northern regions of Cameroon is in charge of the production and marketing 
operations of dairy products that are similar to domestic work because it usually takes place in the kitchen. Similar observations have been reported by Edima et al., (2014) which showed that domestic work is generally reserved for women in these parts of the country. Men represent $4 \%$ in the value chain of lebol are the owners of the dairy bars and are involved in the marketing link. The high representation of the Peulhs at $86 \%$ reflects the fact that they are a people animal breeding. The other ethnic groups represented in this production chain of lebol can be explained by the influence of the environment, the blending of cultures and the adaptation of ethnicities (Edima et al., 2014). With regard to the level of education of operators involved in the processing of lebol in the North Region of Cameroon, it was observed that $84.90 \%$ attend the Koranic school following the rules as perceived by the Islam religion which is the major religion among the Peulhs. With regards to education, only $15.09 \%$ have primary level. Similar trends were also observed by Edima et al., (2012) which showed that in most cases, people working in the dairy sector have little education.

\section{Working environment for lebol production}

The working environment remains an important element in agro-food processing chains. The evaluation of the lebol production environment show that $96 \%$ have no specific site allocated for lebol production. It is done in the family environment like any other domestic activity. The remaining $4 \%$ are production sites close to the markets. These production sites are generally non-compliant with the requirements of the Food Codex.

\section{Material used to process lebol}

Material in contact with food can be a source of contamination. This hypothesis motivated the evaluation of the compliance of the processing equipment of lebol. This survey shows that the material used in the three essential units in the value chain is made of stainless steel, wood, aluminum and plastic (Table 2).

Stainless steel is recommended for processing of dairy products (FAO, 2012). This material must be washable, easy to disinfect and should not interact with milk. The use of nonstandard material can compromise the sanitary and organoleptic qualities of the finished products.

Plastic bottles are recovered for use after consumption of mineral water, cooking oil and fuel cans. The immediate consequences would be biological contamination of milk due to the fact that these containers are difficult to wash and disinfect and chemical contamination because of the primary use of this material (Edima et al., 2014).

In addition, wood material is an auspicious medium for the development of microorganisms because after washing and disinfection it does not dry quickly thus encourage the proliferation of microorganisms (Gran et al., 2002). Although Aluminum is widely used in the design of several products including containers, it remains harmful to human health. It is believed to provoke several cancers such as lung and bladder (InVS, 2003).

\section{The inputs used in processing lebol}

In order to identify and quantify everything that goes into the production of lebol, the have been analyzed. It is observed that there is only one input, the starter. The starter used for seeding milk for lebol production is pendidam (80\% skimmed curd) or kindirmou (whole curdled milk). They are artisanal sourdoughs obtained from spontaneous and uncontrolled fermentations (Libouga et al., 2005). 
Pendidam is an acid fermented milk with a $\mathrm{pH}$ of between 3.55 and $3.95 \mathrm{pH}, \mathrm{pH}$ that promotes the development of acidophilic microorganisms such as lactobacillus ( $L$. fermentum, L. acidophilus) (Jiwoua et al., 1990).

Their metabolism will be oriented towards the production of lactic acid in larger parts and the product will tend to be more acidic. In addition, acidification of milk fats causes loss of its aroma, while diacetyl transformed into acetone exposes the product to oxidation (Tamime et al., 1997).

The $\mathrm{pH}$ of kindirmou fluctuates between 4.2 and 4.7. Germs such as Streptococcus thermophilus found there during their metabolism, will produce lactic acid and other aromatic compounds as diacetyl. The lebol from this fermentation is thought to be highly flavored (Libouga et al., 2005; Edima et al., 2014). The analysis of the two starters suggests a variation in the microorganism profile contained in them, which could eventually result in a variation the aromatic profile and texture of the lebol resulting from these two types of fermentation.

\section{Method of milk processing into lebol}

\section{Raw material supply}

The operators $(74 \%)$ have farms and thus produce milk. The remaining $26 \%$ are actors in the lebol value chain who get supplies from breeders. It shows that the majority of actors (74\%) are milk producers and processors. They have the advantage of not being subject to fluctuations in the milk market in this region. Indeed, during the long dry season (of 8 months) milk production drops from $1.5 \mathrm{~L}$ to 1L /cow (Awono et al., 2014), depriving actors who do not have farms of raw material which compromises their activity during this period.

\section{Lebol production process}

The description of the lebol processing reveals that there is only one process. After receiving the milk, it is sieved, heated, cooled, seeded, fermented and skimmed. The resulting cream is churned out to give lebol, which is washed, kneaded and then packaged (Figure 1).

Delivered milk is sieved to remove foreign bodies. It is then heated over wood fire until boiling. The parameters (time and temperature) of the heating are not controlled. This would affect the effectiveness of this treatment on the inactivation of microorganisms and milk enzymes.

The fragility of its physical-chemical balances (fat emulsion, colloidal protein suspension) can easily lead to physical destabilization, especially under the action of mechanical and thermal shocks (Sboui et al., 2009). Also, a fairly long thermal treatment would lead to the denaturation of the macromolecules of milk, especially caseins (Walstra et al., 1984) and the loss of nutrients such as vitamins (Kessler, 1996). Another consequence of uncontrolled thermal treatment would be the formation of new compounds such as furfural Hydroxymethyl following Maillard's reaction, a reaction between lactose and milk proteins (Brands, 2002; Burton, 1988).

Milk after boiling is left at room temperature to be cooled or in a double boiler. The cooling time and temperature are not controlled and cooling is not done quickly. Indeed, the rapid drop in temperature during cooling makes it possible to make up for the errors of pasteurization.

The cooled milk is seeded and fermented for 18 to 72 hours at room temperature. During fermentation, the time, temperature and concentration parameters of the starter are not defined and controlled. 
Uncontrolled temperature could promote the development of unwanted microorganisms in the product and therefore affect the sanitary and organoleptic qualities of the finished product (Edima et al., 2014). The fermentation temperature should correspond to the optimal temperature range of growth of lactic fermentation (Tamime et al., 1997). Also, fermentation time is not fixed and varies from operator to operator and can thus have an impact on the quality of lebol.

After fermentation, whole milk is skimmed. However, cream yield remains low because skimming is done manually. The recovered cream is churned for about ten minutes by hand. As soon as the lebol forms, the buttermilk is collected and cold water added to it to allow for a firm lebol. The lebol is washed several times for the complete elimination of buttermilk. Unlike the work of Edima et al., (2014) which determined two types of processes, the hot and cold in Adamawa Region, in the North Region, a single type of process, the hot one is observed.

\section{Marketing}

After production, lebol is marketed in locally closest to processing sites. It is sold fresh (in the form of a small ball) or dehydrated and packaged in bottles $(0.35 ; 0.5 ; 1 \mathrm{~L})$. To obtain it, the consumers of lebol can place orders from the operators. In $47 \%$ of cases, clients express satisfaction with of the product.

\section{Lebol Preservation}

Lebol is mainly composed of milk fat, and as a consequence, prone to oxidation reactions of its unsaturated fatty acids. Because of preservation difficulties of lebol, it is customary for it to be consumed or sold immediately after production. This raises the need for the investigation of better preservation methods. It was found that there were three preservation methods, dehydration, $\mathrm{pH}$ decrease and room temperature (Figure 2).

Water activity is reduced by dehydration during heating. Dehydration by wood-fired heating of the lebol allows for a product called Kainadam, equivalent to clarified butter. This reduces the free water in the matrix. The microorganisms in the environment are destroyed by heat. The fat from this dehydration is collected and cooled to room temperature away from the light. However, the fact that the temperature and time of this thermal treatment are not controlled, compromises the nutritional and organoleptic quality of the lebol. Temperatures above 100 or even 150 degrees Celsius will lead to the formation of polymers, cyclical or isomerized compounds. The effect of heat on lebol fatty acids could lead to their oxidation and the formation of free radicals, which are carcinogenic compounds. Similarly, the oxidation of these unsaturated fatty acids can produce the rancid smell of the product.

Lebol can also be preserved by using an acidic medium. Indeed, lebol is soaked in Pendidam, fermented milk at a pH included in 3.55 and 3.9. These acidic conditions will slow or stop the multiplication of non-acidophilic germs and enzyme reactions (Tamime, 2006; Panesar 2011).

However, this $\mathrm{pH}$ would promote the proliferation of microorganisms capable of developing in extreme conditions such as moulds and yeasts as well as all acidophilic microorganisms (Jiwoua et al., 1990). Also, this mode of preservation in pendidam could affect the taste of lebol because of the accumulation of lactic acid in the medium. It is therefore advisable to wash the product before use. The shelf life of lebol in pendidam is limited to 7 days at the moment. 
Table.1 Operators involved in the lebol production chain in the North Cameroon Region

\begin{tabular}{|c|c|c|}
\hline Observations & Variations & Percentages (\%) \\
\hline \multirow{2}{*}{ Gender } & Male & 4 \\
\cline { 2 - 3 } & Female & 96 \\
\hline \multirow{2}{*}{ Ethnicity } & Peulh & 86 \\
\cline { 2 - 3 } & Fali & 7 \\
\cline { 2 - 3 } & Guidar & 7 \\
\hline Level of Education & Non & 85 \\
\hline \multirow{2}{*}{ Religion } & Primary & 15 \\
\hline
\end{tabular}

Table.2 Materials used for the production of lebol in Northern Region of Cameroon

\begin{tabular}{|c|c|c|}
\hline Material & Natures & Use \\
\hline Calabash & wood & $\begin{array}{l}\text { Milk supply and } \\
\text { processing }\end{array}$ \\
\hline Plate & Stainless steel, plastic & $\begin{array}{l}\text { Milk supply, } \\
\text { transformation and } \\
\text { Conditioning }\end{array}$ \\
\hline Can & \multirow{4}{*}{ Plastic } & Milk supply \\
\hline Seals & & \\
\hline Bottle & & Supply and packaging \\
\hline Packaging & & Packaging \\
\hline Pot & Aluminium & \multirow{4}{*}{ Transformation } \\
\hline Ladle & $\begin{array}{l}\text { Wood, plastic, } \\
\text { Aluminium }\end{array}$ & \\
\hline $\begin{array}{l}\text { Bourgal (wooden cross-shaped } \\
\text { thresher) }\end{array}$ & \multirow[t]{2}{*}{ Wood } & \\
\hline $\begin{array}{c}\text { Djoulorou (calabash in the shape of a } \\
\text { bottle) }\end{array}$ & & \\
\hline
\end{tabular}


Fig.1 The production process of lebol used by operators in the North Region of Cameroon

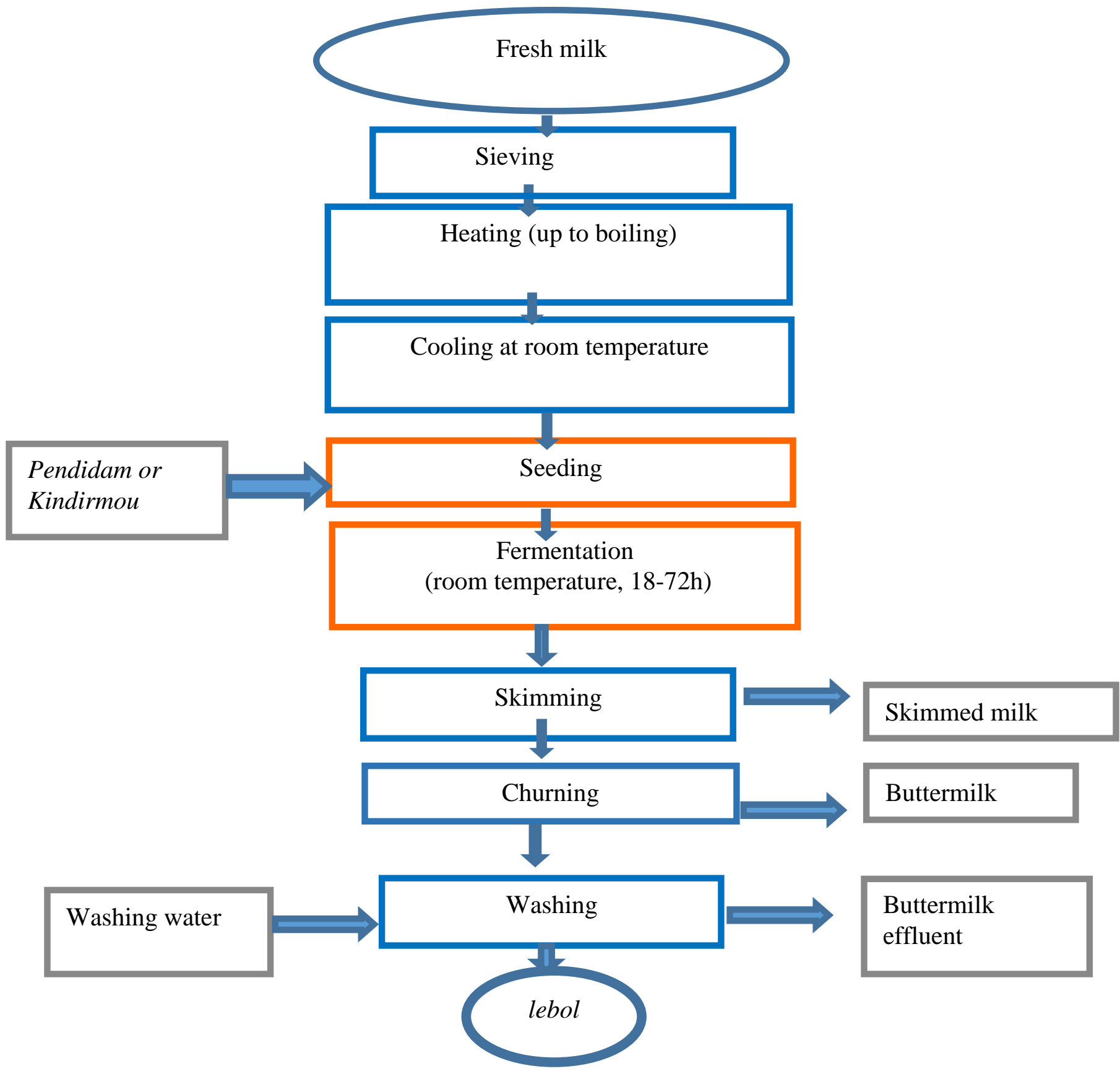


Fig.2 Ways to preserving lebol after manufacture in the North Region of Cameroon

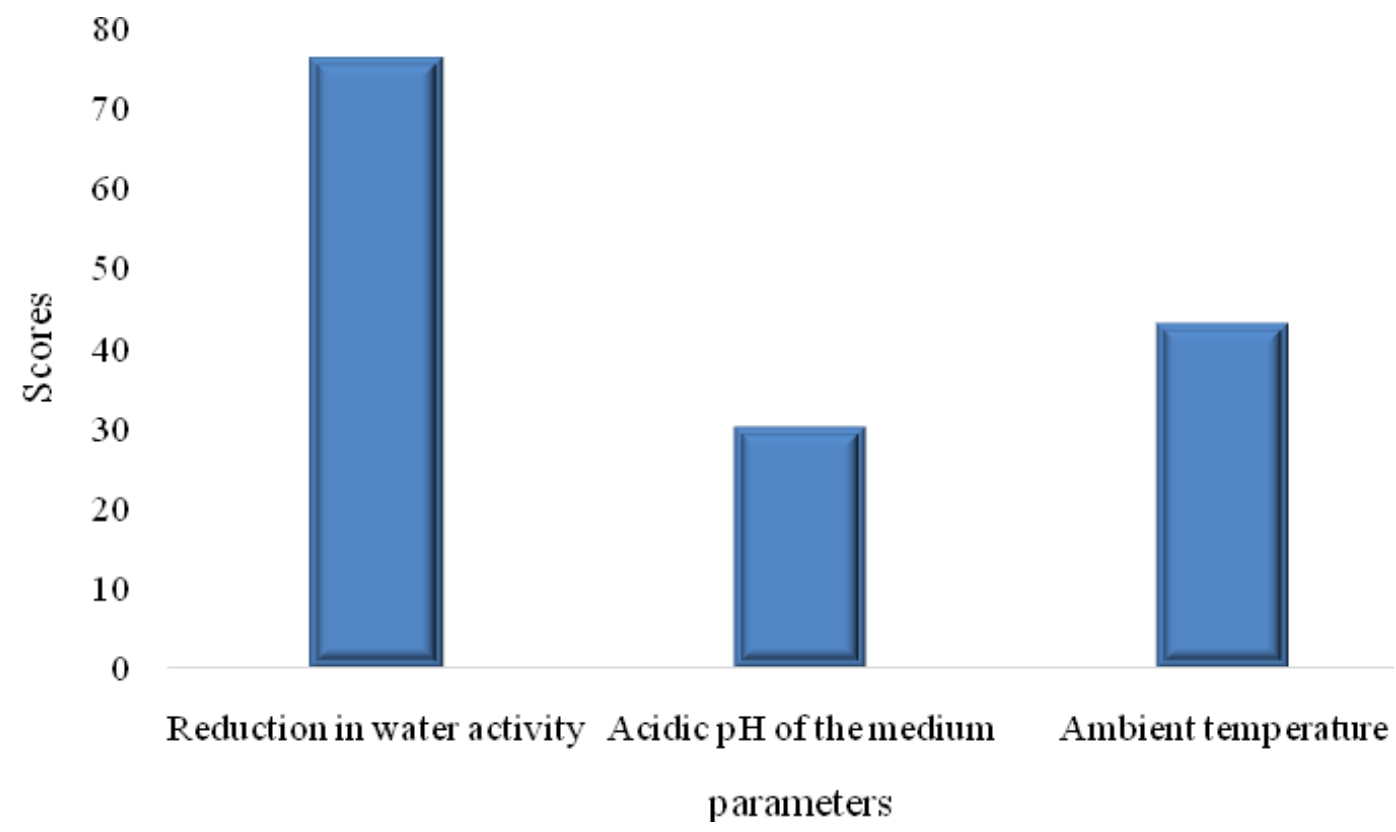

Fig.3 Uses of lebol in Human Food in the Northern Region of Cameroon

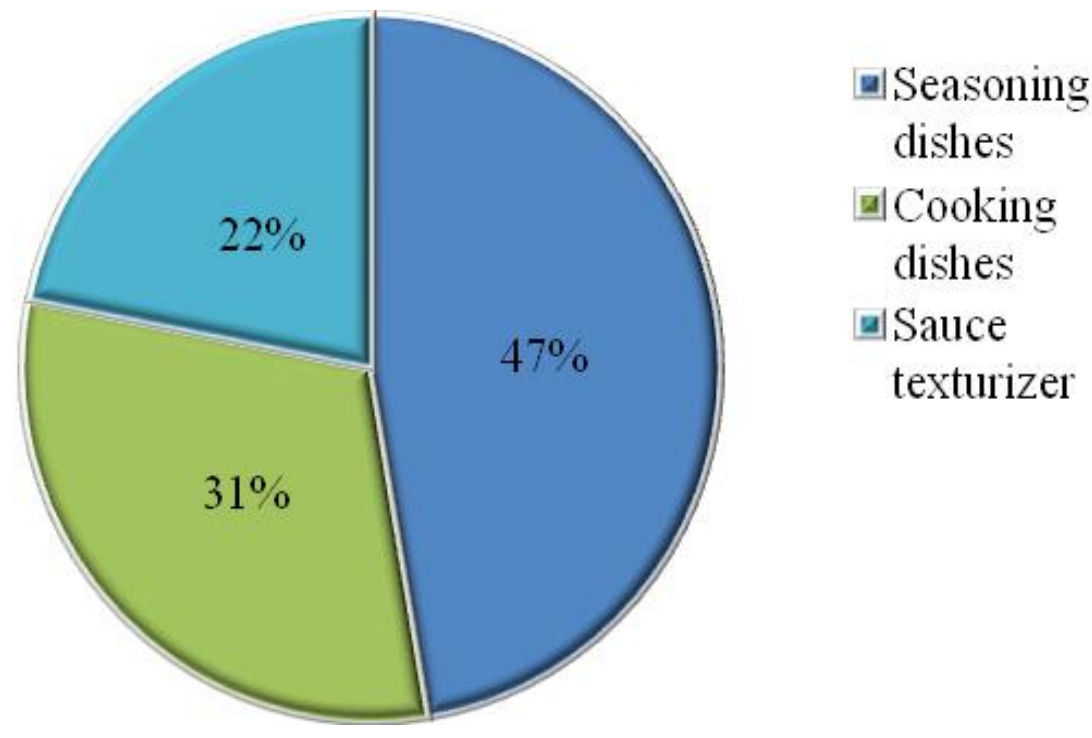


Fig.4 Uses of lebol as therapeutics

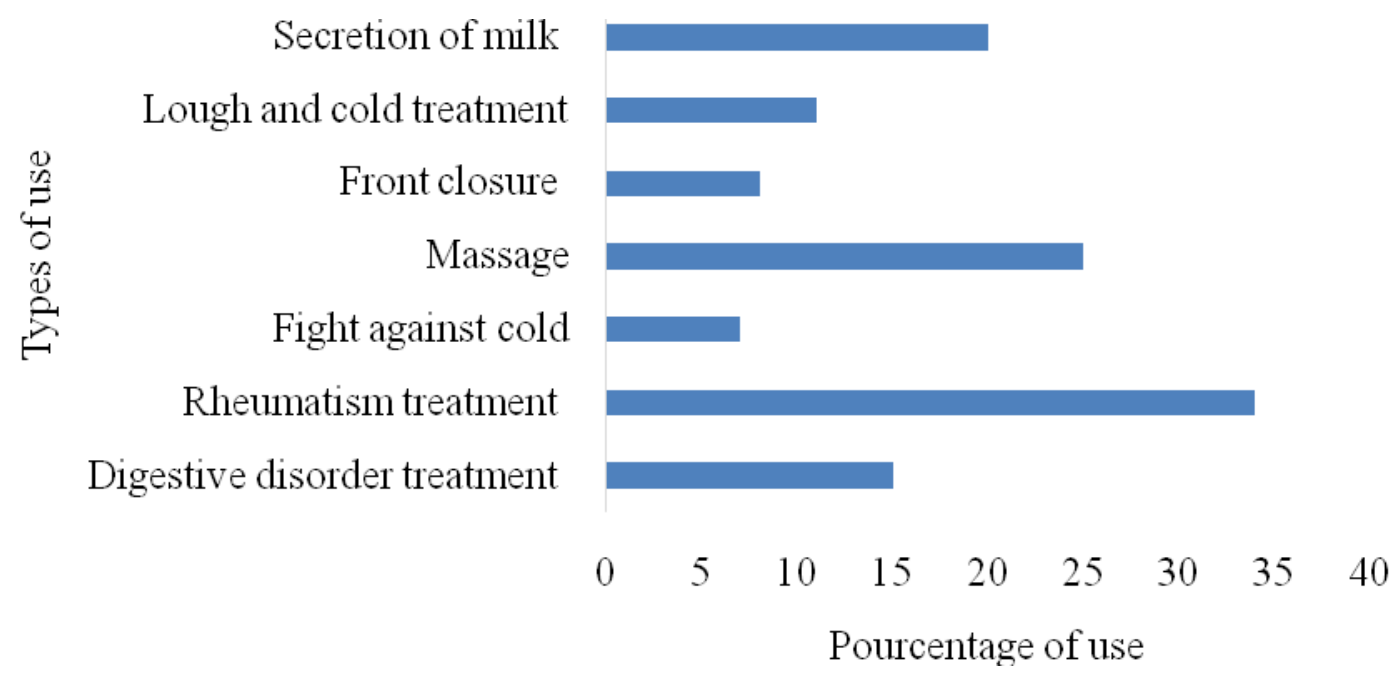

\section{Uses of lebol}

Lebol, which is a local dairy product, is a food that is consumed but is also used in cosmetics and traditional therapy.

\section{Uses of lebol in Food}

In the food field, lebol is used for seasoning of meals at the time of tasting, it is used in the preparation of sauces and vegetables, and also as a taste enhancer etc. (Figure 3). Lebol, a partially dehydrated fatty milk, indeed would consist of $16 \%$ water, $82 \%$ fat, $2 \%$ nitrogen, minerals, and carbohydrates (lactose). It has a high nutritional value and is highly digestible even when consumed in reasonable quantities. It is therefore a source of energy that is assimilated faster by the body. On the other hand, from the point of view of processors, dairy fat is principally responsible for the sensory characteristics of dairy products (Alais, 1984).

\section{Uses of lebol as cosmetics}

Lebol is used for skin (44\%) and hair (56\%) maintenance. According to the accounts of the interviewees, the admirable posture and length of the hair of Peulh women is due to the exclusive use of lebol as a hair cream free of rinsing. Indeed, the saturated and monounsaturated fats contained in lebol play an encapsulating role of, which helps to protect the hair from breakage and retain more hydration of the hair after shampoos. Lebol also makes skin soft and hydrated. Indeed, triglycerides and phospholipids contained in lebol have moisturizing and softening properties (Cotte, 1991).

\section{Uses of lebol in traditional medicine}

Lebol is used in the treatment of several ailments. Figure 4 shows the different percentages of it's use in therapeutic care.

The therapeutic attributes of lebol are thought to be due to the effect of fermentation that results in the synthesis of different healthpromoting metabolites and the decomposition of milk macromolecules into simpler elements that could be bioactive, easy to digest and providing thus all nutritional properties (Shiby and Mishra, 2013). Lebol is used for massage of fractures or sprains and in cases of rheumatism. Lebol also fights against digestive disorders, constipation or diarrhea 
and equally accelerates closure of the fontanelle in babies. It also fights against intestinal ailments and can be inhaled against sinusitis and used for eyes care.

This efficacy in therapeutics can be explained by the presence of sphingolipids, butyric acid, linoleic fatty acid, which play a role in cell differentiation (Shiby and Mishra, 2013). Fermented foods as lebol are potent detoxifers, capable of drawing out a wide range of heavy metals from the body. Additionally, fermented foods supplemented with probiotics are rich in essential nutrients like vitamins B12, B6, K2, biotin, protein, essential amino acids, and fatty acids that fulfill the body needs. Many of the probiotics produce wide variety of antimicrobial substances, for instance, lactic acid, acetic acid, formic acid, propionic acid, ethanol, diacetyl, acetaldehyde, reutericycline, reuterin, fatty acids, and bacteriocins that are inhibitory to pathogens (Jain et al., 2009).

The objective of this study was to analyze the production system of lebol. At the end of this investigation, it is observed that $96 \%$ of the 106 producers surveyed are women. The ethnic groups involved in the production of lebol are the Peulhs, the Guidars and the Fali. The survey revealed only one process type in the production of lebol.

The starter is said to be used as pendidam by $80 \%$ or as kindirmou by $20 \%$ of the producers. However, these starters are not standardized and therefore do not guarantee the quality of the product. In addition to being a culinary ingredient for the seasoning of dishes, lebol is used in traditional medicine and cosmetics. However, the fermentation operation is not yet standardized. Indeed, it requires the development of a starter under controlled conditions. Hence the need to isolate and identify the microorganisms of technological interest that go into the processing of this local dairy product much appreciated by consumers.

\section{References}

Alais C. 1984. Science du lait : principes des techniques laitières. - 4ème édition, Paris : Edition SEPAIC, 814 P.

Awono Enama T., Edima H. C., Biloa D. M. and Etoa F-X. 2014. Milk Production Practices in the Sudano Guinean and Sudano Sahelian Zones of Cameroon, International Journal of Pure \& Applied Bioscience 2 (4): 240-245

Brands C. 2002. Kinetic Modelling of the Maillard Reaction Between Proteins and Sugars. Wageningen University.

Burton, H. 1988. Ultra-High-Temperature Processing of Milk and Milk Products. Elsevier Applied Science, London

Edima H. C., Awono E. T., Ndjouenkeu R. 2013. An Analysis of the Milk Quality in Cameroun. A study in Adamawa Region. Journal of Scientific Research \& Report Article no JSRR.023.10.

Edima H.C, Awono E.T., Biloa D.M, Tchoumkeu H. B. and Etoa F-X. 2014. Valuation of the good hygienic practices on the production of kindirmou and lebol. International journal of current microbiology and applied sciences 3(9) 247-253

Edima H.C., Efangon A.D.D., Mbetoumou M., Biloa D. M., Ndjouenkeu R. 2014. The Characteristics of a food system: The Case of lebol a local butter produced in Ngaoundéré 3rd Cameroon. International journal of current microbiology and applied sciences ISSN: 2319-7706 Volume 3 Number 9. 300-310

Essomba J.M., Dury S., Edjenguele, M., and Bricas, N. 2005. La consommation des produits laitiers a Ngaoundéré au Cameroun : l'émergence des MPE (micro et petites entreprises), in : 
Ressources vivrières et choix alimentaire dans le bassin du Lac Tchad. XI colloque international Méga Tchad. IRD.

FAO (Food agricultural Organisation) (2012) et IDF (International Dairy Federation) : Guide de bonnes pratiques en production laitière. Directives FAO : Production et santé animales. 51pp.

Gran H. M., Mutukumira A. N., Wetlesen A., Narvhus J. A. 2002. Small holder

dairy processing in Zimbabwe: the production of fermented milk products with particular emphasis on sanitation and microbiological quality. Food Control., 13: 161,168.

InVS, 2003 Institute of Health Watch, Evaluation of the risks associated with the exposure of the French population to Aluminium. Rapport d'activité

J Cotte. 1991. Milk, a material of the future for cosmetics. Le Lait, INRA Editions, 1991, 71 (2), pp.213-224.

Jain, S., Yadav, H., and Sinha, P.R. 2009. Probiotic dahi containing Lactobacillus

casei protects against Salmonella enteritidis infection and modulates immune response in mice. Journal of Medicinal Food 12(3): 576-583.

Jiwoua C., Millière J.B. 1990.Lactic flora and enterococci of curd (Pindidam) produced in Adamaoua (Cameroon). Milk, Elsevier/INRA $70(475,486)$.

Kessler H.G. 1996. Lebensmittel- und Bioverfahrenstechnik, Molkereitechnologie. Verlag A. Kessler, Freising, Germany The Rouvreur A. 1989. Sahelians and
Saharans from Chad. Paris, France, L'Harmattan, $535 \mathrm{pp}$.

Libouga D. G., Essia Ngang J.-J. and Halilou H. 2005. Quality of some Cameroonian fermented milks. Food Science. 25: 5366.

MINEPIA, 2015, Ministry of Livestock, Fisheries and Animal Industries, annual report of activities.

Panesar P.S. 2011. Fermented dairy products: Starter cultures and potential nutritional benefts. Food and Nutrition Sciences 2:47-51.

Sboui A., Touhami K., Djegham M. and Belhadj O. 2009. Comparison of the physicochemical composition of camel and bovine milk from southern Tunisia; changes in $\mathrm{pH}$ and acidity at different temperatures. Africa Science: International Journal of Science and Technology, Vol. 5(2), 293-304.

Shiby V. K. and Mishra, H. N. 2013. Fermented milks and milk products as functional foods-A review. Critical Reviews in Food Science and Nutrition 53(5):482-496.

Tamime A. Y. 2006. Fermented Milks. Oxford: Blackwell Science Ltd.

Tamime A. Y. and Marshall V. M. E. 1997. Microbiology and technology of fermented milk. In: Microbiology and Biochemistry of Cheese and Fermented Milk (2nd edition), ed. B.A. Law, 57-152. London: Blackie Academic and Professional.

Walstra, P. and Jennes, R. 1984. Dairy Chemistry and Physics. John Wiley, New York.

\section{How to cite this article:}

Dazeck, D. F. R., H. C. Edima and Nso E. Jong. 2021. Technical Production System of lebol: A Local Dairy Product in Cameroon with Higher Potential. Int.J.Curr.Microbiol.App.Sci. 10(04): 1-11. doi: https://doi.org/10.20546/ijcmas.2021.1004.001 